\title{
Implicações da aplicação de fungicida na adaptabilidade e estabilidade de rendimento de grãos em aveia branca
}

\author{
Implications of fungicide application to adaptability and stability of grain yield in oat
}

\author{
Claudir Lorencetti ${ }^{1}$ Fernando Irajá Félix de Carvalho ${ }^{2}$ Volmir Sergio Marchioro ${ }^{1}$ \\ Giovani Benin ${ }^{1}$ Antônio Costa de Oliveira ${ }^{2}$ Elmar Luiz Foss ${ }^{3}$
}

RESUMO

Vinte genótipos de aveia (Avena sativa L.), testados em 13 ambientes, foram submetidos à análise de adaptabilidade e estabilidade com o objetivo de avaliar o efeito da utilização de fungicida nestes parâmetros, através do modelo de regressão segmentado de CRUZ et al. (1989). A aplicação de fungicida afetou os parâmetros de adaptabilidade $\left(b_{1}\right)$, responsividade $\left(b_{1}+b_{2}\right)$ e estabilidade $\left(\hat{\sigma}_{\delta \mathrm{i}}^{2}\right)$, indicando que as estimativas devam ser realizadas em separado nos ambientes com e sem fungicida. Além disso, o uso de fungicida proporcionou efeito favorável sobre a estabilidade de rendimento de grãos, sendo que quatro genótipos testados mostraram ser estáveis (UPF 19, UPF 20, OR-3 e OR-4), enquanto que na ausência de fungicida todos os genótipos revelaram instabilidade de rendimento de grãos. Entretanto, nenhuma cultivar testada evidenciou características de genótipo ideal, conforme preconizado pelo modelo adotado.

Palavras-chave: Avena sativa L., regressão segmentada, responsividade.

\section{ABSTRACT}

Twenty oat genotypes (Avena sativa L.) tested in thirteen environments were submitted to adaptability and stability analyses aiming at evaluating the effects of fungicide utilization following the segmented regression model of CRUZ et al. (1989). Fungicide application affected the parameters of adaptability $(b)$, responsiveness $\left(b_{1}+b_{2}\right)$ and stability $\left(\hat{\sigma}_{\delta \mathrm{i}}^{2}\right)$ indicating that estimatives must be performed individually in environments with and without fungicide. Fungicide application had a favorable effect on the stability of grain yield, inasmuch as four of the tested genotypes were shown to be stable (UPF 19, UPF 20, OR-3 e OR-4); however, all genotypes revealed instability of grain yield in the absence of fungicide. No tested cultivar showed characteristics of the ideal genotype, as predicted by the adopted model.
Key words: Avena sativa L., segmented regression,
responsiveness.

\section{INTRODUÇÃO}

A cultura da aveia (Avena sativa L.) assume grande importância no período de cultivo de estação fria do ano, principalmente nos estados do sul do Brasil. Porém, seu cultivo se estende desde São Paulo e Mato Grosso até o extremo sul do Rio Grande do Sul. Nesta amplitude de cultivo, a aveia é submetida a condições de ambientes amplamente variáveis determinando, dessa forma, considerável reação diferencial de genótipos frente a variações de ambiente. As interações entre genótipos e ambientes (GxE) são comuns durante as fases de teste nos programas de melhoramento de aveia. Tais interações podem causar dificuldade na seleção de genótipos superiores devido às inconstâncias nas produtividades relativas nos diferentes ambientes (EAGLES \& FREY, 1977).

O componente da interação GxE, apesar de grande importância, não fornece informações sobre o comportamento dos genótipos frente às variações de ambiente (CRUZ \& RAGAZZI, 1997). Desta forma, diversos métodos têm sido propostos para estimar parâmetros de estabilidade e adaptabilidade e caracterizar o desempenho relativo das constituições genéticas (FINLAY \& WILKINSON, 1963; EBERHART \& RUSSELL, 1966; TAI, 1971; CRUZ

\footnotetext{
${ }^{1}$ Engenheiro Agrônomo, doutorando do Curso de Pós-graduação em Agronomia (Fitomelhoramento), Universidade Federal de Pelotas (UFPel). E-mail: lorencettic@zipmail.com.br.

${ }^{2}$ Engenheiro Agrônomo, PhD, Professor do Departamento de Fitotecnia, Faculdade de Agronomia Eliseu Maciel, UFPel, Campus Universitário CP, 354, 96001-970, Pelotas, RS. E-mail: caravalho@ufpel.tche.br. Autor para correspondência.

${ }^{3}$ Engenheiro Agrônomo, Doutor, Professor da Faculdade de Agronomia e Medicina Veterinária, Universidade de Paso Fundo.
} 
et al., 1989) quando submetidas a diferentes condições de ambiente. Para VENKOVSKY \& BARRIGA (1992), a diferença entre os métodos é dada pelos conceitos de estabilidade adotados e pelos procedimentos biométricos utilizados para a estimativa destes parâmetros. Dentre todos os modelos, aqueles baseados em regressão têm sido mais utilizados. Os modelos segmentados devem ser preferidos em relação aos modelos lineares simples sempre que o número de ambientes avaliados for elevado, ou seja, a partir de oito ambientes.

A cultura da aveia é altamente afetada pela ferrugem da folha, moléstia foliar causada pelo fungo Puccinia coronata f.sp. avenae. Em anos favoráveis ao patógeno podem ocorrer perdas superiores a $50 \%$ no rendimento de grãos (MARTINELLI et al., 1994) aumentando, desta forma, a magnitude da interação entre as constituições genéticas e o ambiente. Assim sendo, tem sido recomendada a aplicação de fungicida em ambientes propícios ao desenvolvimento do patógeno, visando a redução da interação GxE e o aumento da estabilidade de rendimento de grãos.

O presente trabalho teve como objetivo caracterizar cultivares recomendadas de aveia branca quanto aos parâmetros de adaptabilidade e estabilidade, bem como, avaliar a influência da aplicação de fungicida sob tais parâmetros quando submetidos a uma ampla variação de condições de ambiente, utilizando o método de CRUZ et al. (1989).

\section{MATERIAL E MÉTODOS}

Os dados experimentais relativos ao caráter rendimento de grãos foram provenientes do Ensaio Brasileiro de Cultivares Recomendados de Aveia, coordenados pela Comissão Brasileira de Pesquisa de Aveia. Os ensaios foram conduzidos na safra agrícola de 2001 nos estados do Paraná, Rio Grande do Sul, São Paulo, Minas Gerais e Mato Grosso, totalizando treze ambientes distintos. Os locais, as entidades responsáveis pela condução dos experimentos, as médias de rendimento de grãos e os coeficientes de variação, são mostrados na tabela 1 .

Todos os ensaios, componentes da pesquisa, foram instalados em delineamento de blocos casualizados, com seis repetições. Três com a aplicação de fungicida e três com ausência de fungicida. De acordo com a necessidade de cada local, foram efetuadas de uma a duas aplicações de fungicida (tebuconazole), na dosagem de $0,75 \mathrm{~L} \cdot \mathrm{ha}^{-1}$. O rendimento de grãos foi transformado em kg.ha- ${ }^{-1}$ a partir da área útil das parcelas que, conforme o local, variaram de 3,0 a $4,25 \mathrm{~m}^{2}$, devido à presença ou ausência de mecanização. Os ensaios foram adubados em conformidade com a análise de solo de cada local, sendo os tratos culturais efetuados, quando necessários ao bom desempenho dos ensaios.

Os dados de rendimento de grãos foram submetidos à análise de variância, considerando os efeitos de genótipos como fixo e os demais aleatórios, sendo realizadas três análises independentes: ambientes com fungicida, ambientes sem fungicida e análise conjunta com todos os ambientes.

Os parâmetros de adaptabilidade e estabilidade foram estimados pela metodologia de CRUZ et al. (1989), baseado na regressão linear segmentada, que tem como parâmetros de adaptabilidade a média $\left(\mathrm{b}_{0 \mathrm{i}}\right)$, a resposta nos ambientes desfavoráveis $\left(b_{1 i}\right)$ e aos ambientes favoráveis $\left(b_{1 i}+\right.$ $\mathrm{b}_{2 \mathrm{i}}$ ); a estabilidade foi avaliada pelos desvios da regressão $\left(\hat{\sigma}_{\delta \mathrm{i}}^{2}\right)$ de cada genótipo em relação as variações de ambiente, conforme o modelo: $\mathrm{Y}_{\mathrm{ij}}=\mathrm{b}_{0 \mathrm{i}}+\mathrm{b}_{1 \mathrm{i}} \mathrm{I}_{\mathrm{j}}+\mathrm{b}_{2 \mathrm{i}} \mathrm{T}\left(\mathrm{I}_{\mathrm{j}}\right)+\delta_{\mathrm{ij}}+\bar{\varepsilon}_{\mathrm{ij}}$, onde: $\mathrm{Y}_{\mathrm{ij}}$ : é $\mathrm{a}$ média de produtividade do genótipo i no ambiente $\mathrm{j}$; $\mathrm{b}_{0 \mathrm{i}}$ : é a média geral de produtividade do genótipo i ao longo de todos os ambientes; $b_{1 i}$ : é o coeficiente de regressão linear que dá a resposta do genótipo i a variação nos ambientes desfavoráveis; $\mathrm{I}_{\mathrm{j}}$ : índice do ambiente; $b_{2 i}$ : é o coeficiente de regressão linear que informa sobre o diferencial de resposta do genótipo i a variação nos ambientes favoráveis; $\mathrm{T}\left(\mathrm{I}_{\mathrm{j}}\right)=0$, se $\mathrm{I} £$ $0 \mathrm{ou} \quad \mathrm{T}(\mathrm{I})=\mathrm{I}+\mathrm{I}^{+}$, se $\mathrm{I}_{\mathrm{j}}>0$, sendo a média dos índices $\mathrm{I}_{\mathrm{j}}^{\mathrm{j}}$ positivos $\mathfrak{j}_{\mathrm{ij}}$ : é o desvio da regressão do genótipo i no ambiente j; $\bar{\varepsilon}_{\mathrm{ij}}$ : erro experimental médio.

As estimativas dos parâmetros de adaptabilidade e estabilidade bem como os testes de hipóteses foram obtidos com o auxílio do programa GENES (CRUZ, 2001).

\section{RESULTADOS E DISCUSSÃO}

Os resultados das três análises de variância, ou seja, experimento com fungicida, experimento sem fungicida e conjunta (com e sem fungicida) foram significativos a $1 \%$ de probabilidade de erro para todos os efeitos principais (genótipos, fungicida, locais), assim como para todas as interações. A significância dos efeitos de genótipos revela a existência de variabilidade genética entre as constituições genéticas avaliadas (Tabela 2). Este fato poderia ser esperado, uma vez que esses genótipos são resultantes de cruzamentos dissimilares, em programas de melhoramento diversos e foram desenvolvidos em distintas condições de ambiente (Tabela 3).

Tanto nas análises de variância dos experimentos individuais (com e sem fungicida), 
Tabela 1 - Relaça de locais com respectivas entidades responsaveis pela conduça dos experimentos. medias de rendimento de gràos dos ambientes com fingicida (CF) s sem lungicida (SF) e coelictentes de variação (CV), no ano agricota de 2001.

\begin{tabular}{|c|c|c|c|c|c|c|}
\hline \multicolumn{2}{|r|}{ Ambientes } & \multirow{2}{*}{ Entidades } & \multicolumn{2}{|c|}{ Média de R(i (that) } & \multicolumn{2}{|c|}{$(\mathrm{V} / \%)$} \\
\hline$N^{2}$ & Locais & & $\mathrm{CF}$ & $\mathrm{SF}$ & $\mathrm{CI}$ & $S F$ \\
\hline $1-14^{1}$ & Guarapuava-PR & FAPA & 4,76 & 3.37 & 5.8 & 9.6 \\
\hline $2-15$ & Ponta Grossa-PR & IAPAR & 3.42 & 2.83 & 16.6 & 16.1 \\
\hline $3-16$ & Pato Branco-PR & CEFET-PR & 3.00 & 2,59 & 13,6 & 13,6 \\
\hline $4-17$ & Londrina-PR & IAPAR & 2,38 & 1,44 & 10.1 & 14.4 \\
\hline $5-18$ & Mauá da Serra-PR & IAPAR & 3.95 & 3.44 & 9.0 & 10.0 \\
\hline $6-19$ & Très de Maio-RS & SETREM & 2,17 & 0.92 & 15,1 & 18.0 \\
\hline $7-20$ & Eldorado do Sul-RS & UFRGS & 1.41 & 0,77 & 12.6 & 20.9 \\
\hline $8-21$ & Lavras-MG & UFLA & 4.54 & 4.59 & 13.5 & 14.9 \\
\hline $9-22$ & Vacaria-RS & UPF: & 4.58 & 3.15 & 7.8 & 10.2 \\
\hline 10)-23 & São Carlos-SP & IMMBRAPA-Pec. Sudeste & 3.07 & 3.17 & 14.1 & 18.2 \\
\hline $11-24$ & Arapoti-PR & CDEA & 5,68 & 5,49 & 9.5 & 10.3 \\
\hline 12.25 & Pelotas-RS & UFPel & 2.48 & 1.07 & 19.7 & 19.2 \\
\hline $13-26$ & Cru/ Alta-RS & Fundacep-lecotrigo & 2.62 & 2,16 & 10,4 & 12.8 \\
\hline
\end{tabular}

1 O primeiro numero indica o ambiente nas analises individuais, tanto com aplicaçao de fungicida como sem. Na analise conjunta (com + sem fungicida) o primeiro número indica o local sem fungicida e o segundo o mesmo local. porem. com tratamento fungicida.

quanto na análise conjunta, o fator local foi o que apresentou maior quadrado médio (Tabela 2), revelando desta forma, a grande importância de se considerar o local no momento da recomendação das cultivares de aveia. Para ALLARD \& BRADSHAW (1964), ambientes distintos são imprescindíveis em um programa de melhoramento para detecção e seleção de genótipos estáveis e adaptados. CARVALHO et al. (1982), trabalhando com aveia em diferentes locais e anos, concluíram que o fator ano foi o de maior importância para a estabilidade desta cultura, sendo o fator local de pequena contribuição. Contudo, os resultados deste trabalho apontaram grande contribuição de locais na modificação do comportamento dos genótipos estudados, concordando com resultados obtidos por FEDERIZZI et al. (1993). O elevado valor do quadrado médio de locais (QML) é dado possivelmente pela ampla extensão de áreas que envolvem os locais utilizados no Ensaio Brasileiro de Cultivares Recomendadas de Aveia (EBCRA), que vão desde Minas Gerais, São Paulo até Pelotas no extremo sul do Rio Grande do Sul. No trabalho de CARVALHO et al. (1982), foram considerados dados de locais do estado do RS, enquanto que, no de FEDERIZZI et al. (1993), além de dados de locais do RS foi incluído um local do PR (Entre Rios), o que permite afirmar que, teoricamente, quanto maior a área que envolve os locais utilizados nos ensaios, mais

Tabela 2 - Fontes de variação, graus de liberdade e respectivos quadrados médios do caráter rendimento de grãos. cm t.ha ${ }^{1}$. obtidos do ensaio brasileiro de cultivares recomendadas de aveia em treze locais.

\begin{tabular}{|c|c|c|c|c|c|c|}
\hline & \multicolumn{2}{|c|}{ Com fungicida } & \multicolumn{2}{|c|}{ Sem fungicida } & \multicolumn{2}{|c|}{ Conjunta } \\
\hline & GI. & Q.M. & GL & Q.M. & GL & Q.M. \\
\hline Genótipos (G) & 19 & $2.09^{* *}$ & 19 & $6.35 * *$ & 19 & $6.91^{* *}$ \\
\hline Fungicida $(\mathrm{F})$ & - & - & - & - & 1 & $189.8 * *$ \\
\hline Locais (L) & 12 & $91.53 * *$ & 12 & $121,4^{* *}$ & 12 & $203.9^{* *}$ \\
\hline$G \times F$ & - & - & - & - & 19 & $1.48^{* *}$ \\
\hline$G \times L$ & 228 & $0.77^{* *}$ & 228 & $1,12^{* *}$ & 228 & $1.52 * *$ \\
\hline $\mathrm{F} \times \mathrm{I}$ & - & - & - & - & 12 & $8.82 * *$ \\
\hline$G \times F \times L$ & - & - & - & - & 228 & $0.37^{* *}$ \\
\hline CV $(\%)$ & - & 12,1 & - & 14,5 & - & 13.2 \\
\hline
\end{tabular}

** Significativo a $1 \%$ de probabilidade de erro $(\mathrm{P}<0,01)$.

Ciência Rural, v.34, n.3, mai-jun, 2004. 
Tabela 3 - Genealogia e ano de lançamento dos 20 genótipos utilizados neste trabalho.

\begin{tabular}{|c|c|c|}
\hline Genótipos & Ano & Genealogia \\
\hline $\mathrm{UPF}^{\prime} 15$ & 1992 & Coker $82-33 / / 11.3376 /$ OA338 \\
\hline UPF 16 & 1993 & Coronado/X1799-2/Sel11 Passo Fundo//X3530-40 \\
\hline UPF 17 & 1994 & Coronado/X1799-2/Sell1 Passo Fundo//X3530-40 \\
\hline UPF 18 & 1999 & UPF $8550238 \times$ UPF 12 \\
\hline UPF 19 & 2000 & UPF $16(90 \mathrm{SA}-30) / 90$ AS-28 (Cor $2 / \mathrm{Ck} 3 / \mathrm{Pendek} / \mathrm{ME} 1563)$ \\
\hline UPFA $^{1} 20$ & 2001 & UPF80197(X2082-2/C18428)/STEELE \\
\hline UFRGS 14 & 1993 & $805165 / / \mathrm{Cor}^{2} / \mathrm{CL}^{3} /$ Pendek / ME1563 \\
\hline UFRGS 15 & 1994 & $\mathrm{Cor}^{2} / \mathrm{Ctz}^{3} / \mathrm{Pendek} / \mathrm{ME} 1563 / \mathrm{C} 16 \mathrm{CRcp} \times / \mathrm{C} 7512 / \mathrm{SRepx} 74 \mathrm{C} 8014$ \\
\hline UFRGS 16 & 1994 & C16 CRCPS / C7512/SR CPX / 74C8014 \\
\hline UFRGS 17 & 1996 & $\mathrm{Cor}^{2} / \mathrm{Ctz}^{3} / \mathrm{Pendek} / \mathrm{ME} 1563 / / 76-29 / 76-23 / 75-28 / \mathrm{Cl} 833$ \\
\hline UFRGS 18 & 1996 & Cocker $81 \mathrm{C} 42 / / \mathrm{Cor}^{2} / \mathrm{Ctz}^{3} / \mathrm{Pendeh} / \mathrm{ME} 1563$ \\
\hline UFRGS 19 & 1999 & $\mathrm{C} 5-21563 / \mathrm{CR} \mathrm{cpx} / \mathrm{SR} \mathrm{cpx} / / 79$ Bordenave sel $\times$ Cocker $81 \mathrm{C} 72 / / \mathrm{COR}^{2} / \mathrm{CTZ}^{3} /$ Pendek / ME 1563 \\
\hline$U_{R R S}^{2} 20$ & 2000 & UFRGS $86 \wedge 1194-2 /$ UFRGS 8 \\
\hline URS 21 & 2000 & UFRGS $10 /$ CTC 8413993 \\
\hline URS 22 & 2002 & UFRGS $841110 \times$ UFRGS 8840211 \\
\hline $\mathrm{OR}^{3} 2$ & 1999 & Desconhecida \\
\hline OR 3 & 2000 & UFRGS $871547 / /$ UFRGS $8 /$ ORI - 892 \\
\hline OR 4 & 2002 & UPF $7 / /$ UFRGS $8 /$ ORI-892 \\
\hline $\mathrm{FAPA}^{+} 4$ & 2002 & UFRGS $881920 \times$ UFRGS 7 \\
\hline $\operatorname{IAC} C^{5} 7$ & 1992 & $\mathrm{~V} 155, \mathrm{ML}-\mathrm{II}-\mathrm{CV}-77-\mathrm{CV} 78-\mathrm{R} 78-79 \mathrm{CV}-79-\mathrm{CV} 80$ (México) \\
\hline
\end{tabular}

Entidades detentoras dos genótipos: 'Universidade de Passo Fundo: 'Universidade Federal do Rio Grande do Sul: ' O.R. Sementes. ${ }^{t}$ Cooperativa Agrária do Paraná; ${ }^{5}$ Instituto Agronômico de Campinas.

divergentes estes serão e, conseqüentemente, maior a importância deste fator na manifestação fenotípica dos genótipos.

A significância da aplicação de fungicida, tanto como fator principal ou nas interações, evidenciou a forte influência da ferrugem da folha sobre o desempenho produtivo dos genótipos (Tabela 2). A significância de FxL indica que a ferrugem da folha atuou diferentemente nos ambientes testados. $\mathrm{Na}$ média geral, a aplicação de fungicida resultou em um incremento de $26 \%$ no rendimento de grãos, o que equivale a $699 \mathrm{~kg} \cdot \mathrm{ha}^{-1}$ (Tabela 4).

A análise de variância padrão informa sobre as estimativas da interação $\mathrm{GxE}$, porém, este procedimento, conforme SMITH et al. (1967), revela informação relativamente pequena para estabilidade fenotípica dos genótipos nos diferentes ambientes. A análise de variância revelou comportamento diferenciado dos genótipos com a modificação do ambiente de cultivo e tratamento com fungicida, justificando, desta forma, as avaliações dos parâmetros de adaptabilidade e estabilidade, propostos neste trabalho. Com isso, foram verificadas as respostas de cada genótipo nos ambientes considerados através do método de CRUZ et al. (1989), o qual busca como genótipo ideal aquele que apresenta média de produtividade alta, adaptado a ambientes desfavoráveis $\left(b_{1}<1\right)$, e seja capaz de responder a melhoria do ambiente $\left(b_{1}+b_{2}>1\right)$, além de apresentar a variância dos desvios da regressão não diferindo de zero (estabilidade).

Os rendimentos médios $\left(b_{0}\right)$ dos genótipos, os parâmetros de adaptabilidade $\left(b_{1}\right)$, de responsividade $\left(b_{1}+b_{2}\right)$ das análises individuais e conjunta são evidenciados na tabela 4. Na maioria dos casos, os genótipos que revelaram média estatisticamente inferior na análise conjunta apresentaram o mesmo comportamento nas análises individuais, como no caso dos genótipos UPF 15, UPF 17, UFRGS 15 e UFRGS 18. Por outro lado, aqueles que foram superiores na análise conjunta, mantiveramse superiores nas análises individuais, como a UPFA 20, OR-2 e FAPA 4. Este fato releva que, mesmo com a aplicação de fungicida, muitos genótipos não alteraram a ordem de posicionamento quanto à média de rendimento de grãos. O genótipo UPF 18 mostrou ser superior apenas nos ambientes sem fungicida, o que se deveu provavelmente pela resistência à ferrugem da folha, a qual se mostrou inferior aos demais (Tabela 4). O prejuízo no rendimento de grãos de aveia causado pela ferrugem da folha pode superar $50 \%$ em genótipos susceptíveis, dependendo do nível 
de infecção (FREY et al., 1973; MARTINELLI et al., 1994). Sendo assim, os genótipos estatisticamente inferiores nas três análises (UPF 15, UPF 17, UFRGS 15 e UFRGS 18) estiveram associados a altos níveis de infecção pelo patógeno. Isso evidencia que, além de sensíveis a ferrugem da folha, o que determinou baixos rendimentos em ambientes sem fungicida, esses genótipos possuem baixo potencial genético, resultando nos baixos rendimentos nos ambientes com fungicida e, conseqüentemente, na média conjunta.

A aplicação de fungicida afetou diferenciadamente os genótipos quanto aos parâmetros de adaptabilidade e responsividade (Tabela 4), contrariamente ao encontrado por FEDERIZZI et al. (1993), no qual somente a média de rendimento foi afetada. Isto possivelmente tenha ocorrido pelo fato do presente trabalho ter considerado maior número de ambientes comparativamente ao de FEDERIZZI et al. (1993), conforme discutido anteriormente. Neste caso, o coeficiente $b_{1}$ variou de 0,65 (UFRGS 15 - sem fungicida) a 1,27 (OR 3 - com fungicida). Em geral, os genótipos que foram pouco afetados pela ferrugem da folha, nos ambientes sem fungicida, apresentaram tanto $b_{1}$ como $b_{1}+b_{2}$ semelhantes nas três análises, como foi observado para URS 21, OR-2 e FAPA 4. Outros genótipos que foram altamente afetados pela moléstia revelaram responder a melhoria do ambiente na ausência de tratamento com fungicida, porém, quando o ambiente foi melhorado (aplicação de fungicida), os coeficientes $b_{1}+b_{2}$ foram significativamente menores do que 1 (UPF 19 e UFRGS 14), mostrando uma tendência a se tornarem menos responsivos na medida em que as condições de ambiente melhorarem. Esses genótipos expressaram todo seu potencial genético de resposta ainda num nível baixo de rendimento do ambiente, mostrandose adaptados a ambientes de baixo a médio rendimento, possivelmente indicando que o aumento de rendimento de grãos é elevado com a aplicação de fungicida atingindo um limite e apresentando dificuldades de

Tabela 4 - Médias gerais $\left(b_{4}\right)$, parâmetros de adaptabilidade $\left(b_{1}\right)$ e responsividade $\left(b_{1}+b_{2}\right)$ do caráter rendimento de grãos, em tha ${ }^{-1}$. $e$ percentagem de incidencia de ferrugem da folha (FFo), obtidos do EBCRA, em treze locais, no ano 2001

\begin{tabular}{|c|c|c|c|c|c|c|c|c|c|c|}
\hline \multirow{2}{*}{ Genótipos } & \multicolumn{3}{|c|}{ Conjunta } & \multicolumn{3}{|c|}{ Com fungicida } & \multicolumn{3}{|c|}{ Sem fungicida } & \multirow{2}{*}{$\mathrm{FFo}(\%)^{\prime}$} \\
\hline & $b_{0}$ & $b_{1}$ & $b_{1}+b_{2}$ & $b_{i}$ & $b_{1}$ & $b_{1}+b_{2}$ & $b_{1}$ & $b_{1}$ & $b_{1}+b_{2}$ & \\
\hline $\mathrm{UPF}^{2} 15$ & $2.64 \mathrm{I}$ & $0.98 \mathrm{~ns}$ & $0,95 \mathrm{~ns}$ & $3.07 \mathrm{I}$ & $0.91 \mathrm{~ns}$ & $1,07 \mathrm{~ns}$ & 2.211 & 0,99 ns & $0.91 \mathrm{~ns}$ & 44 \\
\hline UPF 16 & 3.02 & $1,18^{* *}$ & $1.22^{* *}$ & 3.40 & $1,22^{* *}$ & $1,04 \mathrm{~ns}$ & 2,65 & $1.19 * *$ & $1.28^{* *}$ & 56 \\
\hline UPF 17 & 2,651 & $0,94 \mathrm{~ns}$ & $1,16^{*}$ & $3.05 \mathrm{I}$ & $1.08 \mathrm{~ns}$ & $1,13 \mathrm{~ns}$ & $2.25 \mathrm{I}$ & $0.82 * *$ & $1.09 \mathrm{~ns}$ & 46 \\
\hline UPF 18 & 3.32 & $0,9^{*}$ & $0.9 \mathrm{lns}$ & 3.45 & $1.00 \mathrm{~ns}$ & $1,14 \mathrm{~ns}$ & $3.20 \mathrm{~S}$ & $0.88^{*}$ & $0.85 \mathrm{~ns}$ & 61 \\
\hline UPF 19 & 2.94 & $0.95 \mathrm{~ns}$ & $0.95 \mathrm{~ns}$ & 3,43 & $0.95 \mathrm{~ns}$ & $0.76^{*}$ & 2,45 & $0.91 \mathrm{~ns}$ & $0.90 \mathrm{~ns}$ & 46 \\
\hline$U P F A^{2} 20$ & $3.39 \mathrm{~S}$ & $1,01 \mathrm{~ns}$ & $0.86^{*}$ & $3,66 \mathrm{~S}$ & $0,98 \mathrm{~ns}$ & $1.05 \mathrm{~ns}$ & $3.11 \mathrm{~S}$ & $1.03 \mathrm{~ns}$ & $0.85 \mathrm{~ns}$ & 30 \\
\hline UFRGS 14 & 3.08 & $1,00 \mathrm{~ns}$ & $0.83^{*}$ & 3.55 & $0.87^{*}$ & $0.75^{*}$ & 2.63 & $1.06 \mathrm{~ns}$ & $0.85 \mathrm{~ns}$ & $65 \mathrm{~s}$ \\
\hline UFRGS 15 & $2.52 \mathrm{I}$ & $0.71 * *$ & $1.18^{*}$ & 3.081 & $0.77 * *$ & $1,10 \mathrm{~ns}$ & $1,96 \mathrm{I}$ & $0.65^{* *}$ & $0.88 \mathrm{~ns}$ & $67 \mathrm{~S}$ \\
\hline UFRGS 16 & 2.99 & $1,05 \mathrm{~ns}$ & $0,85^{*}$ & 3,29 & $1.04 \mathrm{~ns}$ & $1,14 \mathrm{~ns}$ & 2,69 & $1.04 \mathrm{~ns}$ & $0.78^{*}$ & 27 \\
\hline UFRGS 17 & 2,86 & $1,04 \mathrm{~ns}$ & $0.85^{*}$ & 3.35 & $0.78^{* *}$ & $1,17 n s$ & 2,36 & $1.05 \mathrm{~ns}$ & $1.09 \mathrm{~ns}$ & 56 \\
\hline UFRGS 18 & $2.65 \mathrm{I}$ & $0.89 *$ & $1.03 \mathrm{~ns}$ & $3.11 \mathrm{I}$ & $0.94 \mathrm{~ns}$ & $0.87 \mathrm{~ns}$ & 2,161 & $0.86 * *$ & $0.94 \mathrm{~ns}$ & 48 \\
\hline UFRGS 19 & 2,92 & $0.84 * *$ & $0,77^{* *}$ & 3.28 & $0.92 \mathrm{~ns}$ & $0.38 * *$ & 2.56 & $0,84^{* *}$ & $0,77^{*}$ & 43 \\
\hline $\mathrm{URS}^{3} 20$ & 3,11 & $1,06 \mathrm{~ns}$ & $1.15^{*}$ & 3.25 & $1,09^{*}$ & $1,26^{*}$ & 2,98 & $1,11^{*}$ & $1,23^{*}$ & 27 \\
\hline URS 21 & $3.46 \mathrm{~S}$ & $0,84^{* *}$ & $0,88 \mathrm{~ns}$ & 3,47 & $0.88^{*}$ & $1,03 \mathrm{~ns}$ & $3,45 \mathrm{~S}$ & $0.88^{*}$ & $1,0 \mathrm{lns}$ & 111 \\
\hline URS 22 & 2,90 & $0.91^{*}$ & $1,15^{*}$ & 3.32 & $0,96 \mathrm{~ns}$ & $0.84 \mathrm{~ns}$ & 2.48 & $0,9 \operatorname{lns}$ & $1.09 \mathrm{~ns}$ & 41 \\
\hline$O R^{4}-2$ & $3.51 \mathrm{~S}$ & $1,14^{* *}$ & $0,88 \mathrm{~ns}$ & $3,77 \mathrm{~S}$ & $1,09^{*}$ & $1,14 \mathrm{~ns}$ & $3.25 \mathrm{~S}$ & $1,16^{* *}$ & $0.85 \mathrm{~ns}$ & $18 I$ \\
\hline OR-3 & 3.20 & $1,27^{* *}$ & $1,16^{*}$ & 3,61 & $1,29 * *$ & $0,96 \mathrm{~ns}$ & 2.78 & $1,26 * *$ & $1.26^{* *}$ & 39 \\
\hline OR-4 & $3.36 \mathrm{~S}$ & $1,23 * *$ & $1,26^{* *}$ & $3.78 \mathrm{~S}$ & $1.26^{* *}$ & $1,28^{*}$ & 2.95 & $1.23^{* *}$ & $1.21^{*}$ & 46 \\
\hline FAPA $^{5} 4$ & $3,38 \mathrm{~S}$ & $1,14^{* *}$ & $0,87 \mathrm{~ns}$ & $3.68 \mathrm{~S}$ & $1.09^{*}$ & $0,94 \mathrm{~ns}$ & $3,10 \mathrm{~S}$ & $1,17^{* *}$ & $1.05 \mathrm{~ns}$ & 22 I \\
\hline $\mathrm{IAC}^{\prime \prime} 7$ & 2,89 & $0.88^{*}$ & $1.17^{*}$ & 3.20 & $0.86^{*}$ & $1.16 \mathrm{~ns}$ & 2.59 & $0.94 \mathrm{~ns}$ & $1.10 \mathrm{~ns}$ & $69 \mathrm{~S}$ \\
\hline Médias & 3.04 & - & - & 3.39 & - & - & 2,69 & - & - & 41 \\
\hline Desv. Pad. & 0.29 & - & - & 0.23 & - & - & 0.40 & - & - & 18 \\
\hline
\end{tabular}

$\mathrm{S}$ e I = média mais 1 (superior) e média menos 1 (inferior) desvio padrão, respectivamente; ${ }^{*} \mathrm{e}^{* *}=$ significativos a 5 e $1 \%$ de probabilidade. respectivamente, pelo teste $t$.

'média de incidència da FFo medida apenas nos ambientes sem fungicidas, pela percentagem da folha atacada pelo patógeno; ${ }^{2}$ Universidade de Passo Fundo: "Universidade Federal do Rio Grande do Sul; †OR. Sementes. 'Cooperativa Agrária do Paraná: "Instituto Agronòmico de Campinas.

Ciência Rural, v.34, n.3, mai-jun, 2004. 
superação. Por outro lado, os genótipos UPF 15, UPF 17, UFRGS 15 e UFRGS 18, que apresentam médias inferiores, revelaram comportamento diferenciado nos distintos ambientes, sendo que, com exceção da UPF 15 , os demais apresentaram $b_{1}<1$ na análise sem fungicida, e apenas o genótipo UFRGS 15 manteve valor de $b_{1}<1$ na análise com fungicida. Para RAIZER \& VENCOVSKY (1999) genótipos com $b_{1}<1$ demonstram não ser tão sensíveis à adversidade do meio, ou seja, podem ser considerados mais rústicos que os demais. Essa característica é muito importante para adaptação a ambientes menos favoráveis, como em condições e solos de menor fertilidade, por exemplo. A análise revelou ainda um grupo de genótipos com adaptação a ambientes favoráveis, grupo este que engloba UPF 16, OR-2, OR-3, OR-4 e FAPA 4. Esses genótipos mostraram responder a melhoria de ambiente nos três ambientes, revelando ainda que mesmo com a melhoria do ambiente, pelo fato do uso do fungicida, este pode ser melhorado mais e esses genótipos continuarão respondendo com incremento no rendimento de grãos, mostrando serem constituições de alto potencial genético, merecendo destaque o genótipo OR-3 nos ambientes sem fungicida e OR-4 nos ambientes com fungicida.

Em ambientes com fungicida, os genótipos mais adaptados a ambientes desfavoráveis foram UFRGS 14, UFRGS 15, UFRGS 17, URS 21 e IAC 7. Houve grande modificação quando não foi aplicado fungicida revelando que desses cinco que apresentaram $b_{1}<1$ nos ambientes com fungicida, apenas a UFRGS 15 e URS 21 mantiveram esta estimativa, porém, este grupo foi acrescido de UPF 17, UPF 18, UFRGS 18, UFRGS 19. Quando da análise conjunta, os genótipos UFRGS 15, URS 21 (assim como nas duas análises individuais), IAC 7 (como em ambientes com fungicida), UPF 18, UFRGS 18, UFRGS 19 (como em ambientes sem fungicida) e URS 22 (somente na análise conjunta) mostraram ser adaptados a ambientes desfavoráveis. Esses dados revelam que, além do fungicida influenciar o desempenho produtivo dos genótipos de aveia, também interferiu no coeficiente $b_{1}$ dos genótipos avaliados.

$\mathrm{Na}$ análise sem fungicida, tabela 4, apenas dois genótipos (UFRGS 16 e UFRGS 19) evidenciaram não responder ao incremento da qualidade do ambiente, tendo $b_{1}+b_{2}<1$, este número foi acrescido nos ambientes com fungicida (UPF 19, UFRGS 14 e UFRGS 19) e também quando foi procedida a análise conjunta (UFRGS 14, UFRGS 16, UFRGS 17 e UFRGS 19). A interferência do fungicida na responsividade dos genótipos, apesar de existir, não foi tão intensa como na média de rendimento e nas estimativas de $b_{1}$.

$\mathrm{Na}$ ausência de fungicida, nenhum dos genótipos apresentou não significativo, evidenciando pouca previsibilidade de comportamento dessas constituições genéticas, ou seja, instabilidade de rendimento de grãos (Tabela 5). Isso era esperado, em face da heterogeneidade de ambientes ocasionado por diferenças de solo, época de semeadura, práticas de cultivo e principalmente, condições ao desenvolvimento da ferrugem da folha entre os locais avaliados. CARVALHO et al. (1982) afirmam que há dificuldade em discriminar genótipos de aveia quanto à estabilidade de rendimento de grãos nas condições do sul do Brasil, provavelmente devido a condições de alta variabilidade do ambiente nesta região. Contudo, na análise com fungicida, os genótipos UPF 19, UPFA 20 , OR-3 e OR-4 revelaram $\hat{\sigma}_{\delta i}^{2}$ não significativo, indicando previsibilidade de comportamento. Com exceção do genótipo UPF 19, os demais que revelaram estabilidade nos ambientes com fungicida também mostraram ser estáveis na análise conjunta. A tendência de variações múltiplas entre os genótipos, ou seja, não seguir um padrão, revelado também pelos demais parâmetros (média de rendimento de grãos, $b_{1}$ e $b_{1}+b_{2}$ ) nas três análises se manteve para o critério de estabilidade. Essas evidências conduzem para análises individualizadas, sempre que os genótipos forem testados em experimentos na presença e ausência de tratamento fungicida, devendo ser evitada análise conjunta de ambientes, caso isto ocorra poderá haver interpretação errônea dos resultados.

$\mathrm{Na}$ análise sem fungicida, os genótipos que se destacaram foram UPF 18 e URS 21, os quais apresentaram média de rendimento superior, adaptada a ambientes desfavoráveis $\left(b_{1}<1\right)$ e responsivas a melhorias de ambiente $\left(b_{1}+b_{2}{ }^{3} 1\right)$, além de apresentarem incidência de ferrugem da folha (FFo) inferior aos demais. Contudo, estes genótipos não evidenciaram estabilidade de rendimento de grãos neste tipo de ambientes. Esses genótipos podem ser de grande interesse para aqueles ambientes de baixa tecnologia, ou seja, em que as condições são pouco favoráveis ao desenvolvimento da cultura e/ou propícias à incidência do patógeno. Nos ambientes com fungicida, destacaram-se os genótipos: UPFA 20 com média superior, porém evidenciando adaptabilidade ampla $\left(b_{1}=1\right)$, com $b_{1}+b_{2}=1$ mostrando ser responsiva a melhoria do ambiente e comportamento previsível ( $\hat{\sigma}_{\delta \mathrm{i}}^{2}=0$ ); OR-4 apresentou média superior $\left(3,78\right.$ t.ha $\left.^{-1}\right)$, com o inconveniente de ser adaptado a ambientes favoráveis $\left(\mathrm{b}_{1}>1\right)$, responsiva 
Tabela 5 - Estimativas dos parâmetros de estabilidade $\left(\hat{\sigma}_{\delta}^{2}\right)$ e dos coeficientes de determinação $\left(R^{2}\right)$. do caráter rendimento de grãos. em t.ha ${ }^{-1}$. obtidos do Ensaio Brasileiro de Cultivares Recomendadas de Aveia. em treze locais. no ano 2001.

\begin{tabular}{|c|c|c|c|c|c|c|}
\hline \multirow[b]{2}{*}{ Genótipos } & \multicolumn{2}{|c|}{ Conjunta } & \multicolumn{2}{|c|}{ Com fungicida } & \multicolumn{2}{|c|}{ Sem fungicida } \\
\hline & $\hat{\sigma}_{\delta i}^{2}$ & $\mathrm{R}^{2}(\%)$ & $\hat{\sigma}_{\delta \mathrm{i}}^{2}$ & $R^{2}(\%)$ & $\hat{\sigma}_{\delta i}^{2}$ & $\mathrm{R}^{2}(\%)$ \\
\hline UPF 15 & $0,14 * *$ & 91 & $0,12^{* *}$ & 90 & $0.19^{* *}$ & 90 \\
\hline UPF 16 & $0.16^{* *}$ & 93 & $0.25^{* *}$ & 90 & $0,10^{* *}$ & 96 \\
\hline UPF 17 & $0,36^{* *}$ & 83 & $0,35 * *$ & 85 & $0,44^{* *}$ & 80 \\
\hline UPF 18 & $0,24^{* *}$ & 85 & $0,20^{* *}$ & 89 & $0.24^{* *}$ & 86 \\
\hline UPF 19 & $0.12^{* *}$ & 91 & $0.02 \mathrm{~ns}$ & 96 & $0.20^{* *}$ & 89 \\
\hline UPF 20 & $0,016 \mathrm{~ns}$ & 97 & $0,002 \mathrm{~ns}$ & 97 & $0.04 * *$ & 96 \\
\hline UFRGS 14 & $0,10^{* *}$ & 92 & $0,11^{* *}$ & 89 & $0.06^{* *}$ & 96 \\
\hline UFRGS 15 & $0.69 * *$ & 65 & $0,33^{* *}$ & 77 & $1.17 * *$ & 51 \\
\hline UFRGS 16 & $0,13^{* *}$ & 92 & $0,11^{* *}$ & 93 & $0.19 * *$ & 90 \\
\hline UFRGS 17 & $0.27 * *$ & 86 & $0.24 * *$ & 83 & $0.28 * *$ & 89 \\
\hline UFRGS 18 & $0.55 * *$ & 74 & $0.34 * *$ & 80 & $0.93^{* *}$ & 65 \\
\hline UFRGS 19 & $0.21^{* *}$ & 84 & $0.066^{* *}$ & 92 & $0.29^{* *}$ & 83 \\
\hline URS 20 & $0.26^{* *}$ & 88 & $0.18^{* *}$ & 92 & $0.27 * *$ & 91 \\
\hline URS $21^{\circ}$ & $0.57^{* *}$ & 70 & $0.55^{* *}$ & 72 & $0.55^{* *}$ & 77 \\
\hline URS 22 & $0.27^{* *}$ & 85 & $0.27^{* *}$ & 83 & $0.37 * *$ & 84 \\
\hline OR-2 & $0,18^{* *}$ & 91 & $0,17^{* *}$ & 91 & $0.29 * *$ & 89 \\
\hline OR-3 & $0,07 \mathrm{~ns}$ & 96 & $0.0 \mathrm{lns}$ & 98 & $0.14^{* *}$ & 95 \\
\hline OR-4 & $0,08 \mathrm{~ns}$ & 96 & $0.007 \mathrm{~ns}$ & 98 & $0,19^{* *}$ & 94 \\
\hline FAPA 4 & $0,12 * *$ & 93 & $0,11^{* *}$ & 93 & $0,20^{* *}$ & 92 \\
\hline $\mathrm{IAC} 7$ & $0.21^{* *}$ & 87 & $0,46^{* *}$ & 75 & $0.06^{* *}$ & 95 \\
\hline
\end{tabular}

** = diferentes de zero, significativos $1 \%$ de probabilidade de erro pelo teste $\mathrm{F}: \mathrm{S}$ e I = média mais $\mathrm{l}$ (superior) e média menos $\mathrm{I}$ (inferior) desvio padrão, respectivamente.

a melhoria de ambientes $\left(b_{1}+b_{2}>1\right)$, e com desvios da regressão não diferindo de zero $\left(\hat{\sigma}^{2}=0\right)$. O genótipo OR-4 deverá ser o preferido quand $\delta$, a priori, é sabido que os ambientes serão favoráveis ao desenvolvimento da cultura, pela utilização de altos níveis tecnológicos pelos agricultores.

Os altos valores da estimativa de $\mathrm{R}^{2}$, evidenciado para a grande maioria dos genótipos avaliados revela o ajuste do modelo adotado em explicar a variação dos dados. Entretanto, nenhum genótipo apresentou biótipo ideal de constituição genética conforme preconizado pelo modelo de CRUZ et al. (1989).

\section{CONCLUSÕES}

A utilização de fungicida é um fator decisivo na determinação de estimativas dos parâmetros de adaptabilidade e estabilidade para o rendimento de grãos, justificando, desta forma, o emprego de estimativas individualizadas em ambientes distintos, considerando que a aplicação de fungicida evidencia efeito favorável no incremento da estabilidade fenotípica.

\section{REFERÊNCIAS BIBLIOGRÁFICAS}

ALLARD, R.W.; BRADSHAW, A.D. Implications of genotypesenvironment interaction in applied plant breeding. Crop Science, Madison, v.4, p.503-508, 1964.

CARVALHO, F.I.F. et al. Analysis of stability parameters and of genotype $\mathrm{x}$ environment interaction in oats grain yield in Rio Grande do Sul (Brazil). Revista Brasileira de Genética, Ribeirão Preto, v.5, p.517-532, 1982.

CRUZ, C.D. Programa genes: aplicativo computacional em genética e estatística. Viçosa : UFV, 2001. 648p.

CRUZ, C.D.; REGAZZI, A.J. Modelos biométricos aplicados ao melhoramento genético. 2.ed. Viçosa : UFV, 1997. 390p.

CRUZ, C.D.; TORRES, R.A.; VENCOVSKY,R . An alternative approach to the stability analysis proposed by Silva e Barreto. Revista Brasileira de Genética, Ribeirão Preto, v.12, p.567-580, 1989.

Ciência Rural, v.34, n.3, mai-jun, 2004. 
EAGLES, H.A.; FREY, K.J. Repeatability of the stability-variance parameters in oats. Crop Science, Madison, v.17, p.253-256, 1977.

EBERHART, S.A.; RUSSELL, W.A. Stability parameters for comparing varieties. Crop Science, Madison, v.6, n.1, p.36-40, 1966.

FEDERIZZI, L.C. et al. Estabilidade do rendimento de grãos em aveia: efeito do uso de fungicida. Pesquisa Agropecuária Brasileira, Brasília, v.28, n.4, p.465-472, 1993.

FINLAY, K.W.; WILKINSON, G.N. The analysis of adaptation in a plant breeding programme. Australian Journal of Agriculture Research, v.14, p.742-754, 1963.

FREY, K.J. et al. Management of host resistance genes to control disease loss. Indian Journal of Genetics and Plant Breeding, Nova Delhi, v.39, p.10-21, 1973.
MARTINELLI, J.A. et al. Redução no rendimento de grãos de aveia em função da severidade da ferrugem da folha. Summa Phytopathologica, Jaboticabal, v.40, p.116-118, 1994.

RAIZER, A.J.; VENCOVSKY, R. stabilidade fenotípica de novas variedades de cana-de-açúcar para o estado de São Paulo. Pesquisa Agropecuária Brasileira, Brasília, v.34, n.12, p.22412246, 1999.

SMITH, R.R. et al. Phenotype stability in soybean populations. Crop Science, Madison, v.7, p.590-592, 1967.

TAI, G.C.C. Genotypic stability analysis and its application to potato regional traits. Crop Science, Madison, v.11, p.184-190, 1971.

VENCOVSKY, R.; BARRIGA, P. Genética biométrica no fitomelhoramento. Ribeirão Preto : Sociedade Brasileira de genética, 1992. 496p. 